\title{
Inclusión en Educacion Superior: Retos y Mitos.
}

\author{
Inclusion in Higher Education: Challenges and Myths.
}

Actualmente la inclusión es un término que está tomando importancia en el mundo y el Perú no es la excepción. Muchos países desarrollados conocen este término a la perfección, o por lo menos, lo necesario, para llevar a cabo programas de educación; sin embargo, en el Perú, este tema en educación, a pesar de su necesidad, aun suena desconocido y nuevo a la vez. En el pasado, cuando se crearon y desarrollaron las primeras universidades públicas y privadas, la inclusión en la educación superior no ha sido prioridad para los distintos gobiernos, por esta razón, el estado peruano, en su intento de tener un país con una mejor educación, plantea soluciones alternas mediante programas que denomina "Inclusión educativa" en sus distintas modalidades.

Sin duda, la aparición de universidades privadas de manera indiscriminada en la década de los noventa contribuyó con la masificación de la educación superior en el Perú, este suceso ha posibilitado el ingreso de distintos sectores sociales que históricamente han sido excluidos de los espacios educativos, sobre todo de la educación superior (1) a pesar de mayores oportunidades para los estudiantes, las universidades nacionales de gran prestigio que estaban acostumbrados a recibir estudiantes académicamente preparados, registran hoy, el ingreso de estudiantes con menor preparación pre-universitaria, además alumnos con menor edad al que estaban acostumbrados.

El principio de la inclusión educativa fue incierto y considerado trivial por una parte de la población peruana. El proyecto inicial fue deteriorándose debido a que las universidades públicas tomaron caminos distintos; algunos enfatizaron en un proyecto político, otros perdieron docentes de calidad debido a que los honorarios de los mismos no cubrían sus expectativas y con el auge de las universidades privadas, migraron hacia ellas. La ambición por una masificación ha contribuido, entre otras cosas, al aumento de las universidades privadas, situación que ha implicado una promoción y enraizamiento de las lógicas político-económicas propias del sistema neoliberal, derivando en "un proceso contradictorio de desigualdad en el acceso a la enseñanza superior para las grandes mayorías y en una excesiva comercialización y privatización de sus servicios"(1)

Aunque hoy los distintos programas ofrecen calidad y esperanza a los alumnos para cumplir sus sueños, la mejora de la economía peruana permite que el negocio de la educación superior sea más apetecible, debido a ello aparecen universidades privadas con fines de lucro a diestra y siniestra contribuyendo con la baja en la calidad de la enseñanza universitaria y compitiendo con las universidades públicas "serias" con presupuestos tradicionalmente magros, en algunos casos, han llegado a establecer filiales en la capitales de las diversas regiones del país sin ningún organismo que regule o lo acredite tal situación.

Ante la desorientación inicial de los padres, estudiantes y del propio sector gubernamental, el estado toma la iniciativa de hacer las correcciones respectivas ya que el modelo educativo no era inclusivo debido a que la educación superior no estaba llegando a la población lejana y más bien se estaba concentrando en las poblaciones con mayor poder adquisitivo, de esta manera la brecha académica cada vez era mayor, diagnosticado la situación, el gobierno inicia la visualización de los centros universitarios acreditados y con excelencia académica; sin embargo, los costos de las pensiones en estos centros son difíciles de alcanzar por los alumnos y padres de familia de los estudiantes de 
escasos recursos que acuden desde distintas regiones del país. La inclusión en la educación superior se mide a partir del número de estudiantes por cada 10.000 habitantes de un país (2).

Es en esta situación, que el estado se involucra en la inclusión en educación superior, orientando a lograr que las instituciones acepten una diversidad racial, cultural y sexual semejante a la que existe en el seno de la sociedad, procurando corregir discriminaciones históricas que han conducido a la situación de desigualdad por la que atraviesan esos grupos (3), convocando así a estudiantes, al ingreso en las universidades de trayectoria reconocida, alumnos de postgrado para continuar con los estudios de maestría y doctorado, tanto en las universidades nacionales e internacionales, en esta decisión, las autoridades de turno identifican centros universitarios que reúnen requisitos mínimos para una adecuada enseñanza donde los estándares educativos son altos, por lo que deciden apoyar a los estudiantes de distintas regiones del país de escasos recursos económicos, con la finalidad de que una vez finalizados sus estudios retornarán a sus comunidades y regiones para poner en práctica lo aprendido en estos centros de estudio, en algunos casos se trata de jóvenes que jamás hubieran podido acceder a estos centros universitarios, ojalá que el proyecto no solo sea un ensayo, sino sea el reto mayor que debe tener como principal objetivo el estado peruano.

Ahora le toca a la comunidad universitaria en general y estudiantes en especial, aceptar y buscar la promoción y el tipo de estrategias en los alumnos y alumnas se basan en modelos tradicionales (4), adaptarse a la situación de tener nuevos compañeros de estudios con distintas costumbres y hábitos por rasgos físicos corporales (color de piel, ojos, etc.) y modo de hablar o pueblo de origen (5), incluso otro idioma a los que estaban ya familiarizados.

Este será un nuevo reto de convivencia y romperá muchos mitos creados sin ningún fundamento, sobre todo de INCLUSION EDUCATIVA a los que no cabe duda redundarán en beneficio de la educación superior peruana al servicio del país y sus regiones. Hay que esperar un tiempo prudente para hacer la evaluación correspondiente y ampliar la cobertura de esta política dirigida a la equidad, inclusión e interculturalidad en educación superior.

\section{REFERENCIAS BIBLIOGRÁFICAS.}

1. Villarroel V, Guerrero D, Hernández V, Maldonado M, Román D. Análisis de los significados de estudiantes universitarios indígenas en torno a su proceso de inclusión a la educación superior. Psicoperspectivas. 2014 Jan;13(1):35-45.

2. Fernández Darraz E, Reisz R, Stock M. Entre democracia y dictadura: inclusión en la educación superior en países de Latinoamérica, Europa Oriental y Europa Occidental (1950-2000). Calid En Educ. 2013 Jun;(38):245-75.

3. Chiroleu A. Public policies for inclusion in higher education the Argentinian and Brazilian cases. -Posições. 2009 Aug;20(2):141-66.

4. Villarroel V, Bruna D. Reflexiones en torno a las competencias genéricas en educación superior: Un desafío pendiente. Psicoperspectivas. 2014 Jan;13(1):22-34.

5. Chávez Achong J. Universidad Nacional Agraria La Molina- Peru: inclusão social e discriminação social. Rev Lusófona Educ. 2013 Jan;(24):141-55.

Mg. Fredy Gutierrez $V^{1, a, b}$

Editor-Jefe

\footnotetext{
Asociación Peruana de Cirugía Bucal y Maxilofacial. Lima, Perú.

a Especialista en Ortodoncia y Cirugía Oral y Maxilofacial.

b Magister en Estomatología.
} 